\title{
Personal and Contextual components of Resilience mediate Risky Family Environment's effect on Psychotic-Like Experiences.
}

\author{
Rodolfo Rossi ${ }^{1}$, Alberto Collazzoni ${ }^{2}$, Dalila Talevi ${ }^{2}$, Dino Gibertoni ${ }^{3}$,Eleonora Quarta ${ }^{2}$, Alessandro Rossi ${ }^{2}$, \\ Paolo Stratta ${ }^{2}$, Giorgio Di Lorenzo ${ }^{1}$, Francesca Pacitti ${ }^{2}$.
}

\begin{abstract}
${ }^{1}$ Department of Systems Medicine, University of Rome Tor Vergata, Rome, Italy.
Correspondence:

Rodolfo Rossi,

Department of Systems Medicine, University of Rome Tor Vergata

Via Montpellier 1, 00133, Roma, Italy

Email: rudy86.rossi@gmail.com
\end{abstract}

${ }^{2}$ Department of Biotechnological and Applied Clinical Sciences, University of L'Aquila, L'Aquila, Italy.

${ }^{3}$ Department of Biomedical and Neuromotor Sciences, University of Bologna, Bologna, Italy.

\section{Abstract}

Background: Psychotic-like experiences index an increased risk for subsequent psychotic disorders. A risky family environment is a well-established risk factor for psychotic-like experiences, however different contextual and personal factors may differentially mediate their effect on psychotic-like experiences, including different aspects of resilience.

Objective: In this study we propose a two-dimension model of resilience. Our aim is to address separately the mediational role of personal and contextual resilience factors between a risky family environment and PLE in a community sample.

Methods and Materials: Five hundred University students completed an on-line questionnaire including the Resilience Scale for Adults, the 16-item version of the Prodromal Questionnaire and the Risky Family Questionnaire.

Mediation was assessed using Structural Equation Modelling with bootstrapping estimation of indirect effect.

Results: Direct effect of Personal and Contextual resilience on Psychotic-like experiences were respectively -0.69 [$0.97,-0.41](\mathrm{p}<0.001)$ and $-0.19[-0.58,0.20](\mathrm{ns})$; indirect effects through personal resilience was $0.03[0.01,0.04]$ $(\mathrm{p}<0.001)$. Personal resilience mediated $27.4 \%$ of the total effect of risky family environment on psychotic-like experiences.

Discussion: Personal resilience, but not contextual resilience, mediated the effect of a risky family environment on Psychotic-like experiences. Poor personal resilience may represent an individual risk factor that transmits the effect of risky family environment on psychotic-like experiences, and could represent a central aspect of individualized prevention and treatment strategies.

\section{Keywords}

Resilience; Psychotic-like experience; Childhood Adversity; mediation 
medRxiv preprint doi: https://doi.org/10.1101/2020.05.18.20106237; this version posted May 26, 2020. The copyright holder for this preprint

(which was not certified by peer review) is the author/funder, who has granted medRxiv a license to display the preprint in perpetuity.

All rights reserved. No reuse allowed without permission.

\section{Background}

Psychotic-Like Experiences (PLEs) are sub-clinical psychotic phenomena relatively common in the general population, with an estimated lifetime prevalence of about 7\% (Linscott \& Van Os, 2013; McGrath et al., 2015), peaking during early adolescence and settling to a plateau in early adulthood (Thapar et al., 2012; Zammit et al., 2013). PLEs are conceptualized within the proneness-persistence-impairment model of psychotic disorders: individuals with a genetically-determined vulnerability to psychosis exposed to a number of risk factors, gradually increase the risk of having PLE and eventually transitioning to a psychotic disorder going through a prodromal at-risk mental state, although the exact rate of conversion is still a matter of debate. Such model is founded on the evidence that PLE and Psychotic Disorders share the same risk factors, including perinatal (Glaser et al., 2010), developmental (Thomas et al., 2009), neuropsychological (Horwood et al., 2008; R. Rossi et al., 2016) and emotional factors.

Childhood adversities, including a familial environment characterized by violence, unreliable or chaotic parenting style and neglect, are among the most well-established and replicated risk factors for all the stages of the psychosis continuum (Morgan \& Gayer-Anderson, 2016). On the one side of the psychosis spectrum, childhood adversities are associated with PLE (Fisher et al., 2013; McGrath et al., 2017, 2015). On the other extreme, a recent meta-analysis has established a significant association between childhood adversities and psychosis (Varese et al., 2012) with odd ratios of 2.78. Between these two extremes, childhood adversity has been associated with persistence of psychotic experiences (Trotta, Murray, \& Fisher, 2015) and Ultra-high risk (UHR) states (Peh, Rapisarda, \& Lee, 2019).

The mechanisms through which childhood adversities and a risky family environment convey a heightened risk for PLE and psychotic disorders are still a matter of research. One of the leading lines of research is focusing on the putative psychological and cognitive mediators of the impact of childhood adversities on the psychotic continuum. To name a few, source monitoring deficits (Serrone et al., 2019) and dissociation (Bentall et al., 2014) are well-known mediators between sexual abuse and auditory hallucinations; reasoning biases mediate the development of paranoia (Freeman $\&$ Garety, 2014); and affective states (anxiety, depressive symptoms, external locus of control, and low self-esteem) have been shown to mediate the development of PLE (Fisher et al., 2013). An extensive systematic review by Williams and colleagues (Williams, Bucci, Berry, \& Varese, 2018) has classified mediators in post-traumatic sequelae, affective disturbance and dysregulation, cognitive processes and appraisal of subsequent stressors.

Among the psychological mediators of potential interest for the psychotic continuum, resilience has received large attention.

Resilience is the capacity of adaptively overcoming stress and adversity while maintaining normal, or developing a better psychological functioning.

Resilience is a broad multimodal construct (Stainton et al., 2018) that comprises different personal and contextual aspects. Personal factors, also termed assets, include individual characteristics such as competence, coping skills, and self-efficacy. Contextual factors, or resources, are positive factors that are external to the individual, and include parental support, social connectedness or community organizations (Fergus \& Zimmerman, 2005). 
medRxiv preprint doi: https://doi.org/10.1101/2020.05.18.20106237; this version posted May 26, 2020. The copyright holder for this preprint

(which was not certified by peer review) is the author/funder, who has granted medRxiv a license to display the preprint in perpetuity.

All rights reserved. No reuse allowed without permission.

Resilience has been shown to be associated with risk factors for PLEs. For example, social support has shown a protective effect to PLEs against childhood adversity (Crush et al., 2018). On the other hand, some individual assets of resilience, such as stress sensitivity or self-confidence may be negatively affected by childhood adversity in the first place (Rauschenberg et al., 2017). When assessing subclinical outcomes in general population samples, resilience has been shown to mediate the effect of childhood adversities on PLE (Sengutta, Gawęda, Moritz, \& Karow, 2019).

In clinical samples, resilience has been linked to different outcomes: for example, in psychotic patients low resilience has been related to depressive symptoms (A. Rossi et al., 2017) conveying suicidal risk to depressed patients (Rossetti et al., 2017), while higher levels of resilience participate in the process of personal recovery (A. Rossi et al., 2018) in patients with schizophrenia.

Under a psychometric perspective, a bi-factorial structure of the RSA has been recently confirmed using CFA in its Spanish version (Morote, Hjemdal, Uribe, \& Corveleyn, 2017). Separating 'contextual' interpersonal from intrapersonal resilience resources may help elucidating some psychological mediational mechanisms underlying the effect of childhood adversity risky family environment on PLEs.

In the operationalization behind the Resilience Scale for Adults (RSA) (Friborg, Barlaug, Martinussen, Rosenvinge, \& Hjemdal, 2005; Friborg, Hjemdal, Rosenvinge, \& Martinussen, 2003), both personal and social resources are proposed. This distinction is somewhat similar to the definition of resilience-related interpersonal resources and individual assets proposed by Fergus and Zimmermann (Fergus \& Zimmerman, 2005).

Following up the call to conceptualize resilience as a multimodal construct, the aim of this study is to examine an higher-order bi-factorial model of resilience made up of personal assets and interpersonal resources, and to separately address the mediational role of personal and interpersonal resilience factors between childhood adversity and PLE in a community sample. In particular, we test the hypothesis that exposure to a risky family environment could differentially affect resilience that in turns could exert a weakened protective effect on PLEs.

\section{Materials and Methods}

\section{Participants}

Participants were all bachelor and master's degree students at University of L'Aquila. The recruitment was conducted online with the help of ads on different social networks related to the University. All participants provided written informed consent and the study was approved by the local ethics committee. Institutional Review Board code of this study is $22562 / 21.05 .18$

In order to ensure the validity participants' answers, six "attention checks" were distributed throughout the entire survey, asking participants to answer in a particular way (i.e. "please answer "yes" to this question"). Two thousand one hundred and sixty-seven volunteers visited the online survey, but only five hundred gave the consent, answered correctly all of the attention checks and, filled in all of the questionnaires.

\section{Measures}

Risky Family Questionnaire 
medRxiv preprint doi: https://doi.org/10.1101/2020.05.18.20106237; this version posted May 26, 2020. The copyright holder for this preprint (which was not certified by peer review) is the author/funder, who has granted medRxiv a license to display the preprint in perpetuity. All rights reserved. No reuse allowed without permission.

Childhood Adversity was assessed using the Risky Family Questionnaire (RFQ), a 13-items retrospective self-report questionnaire on a 5-point likert scale derived from the Adverse Childhood Experiences questionnaire (ACE-q) by Felitti et al., (Felitti et al., 1998). RFQ investigates the exposure to harsh parenting during childhood. Examples of the items are: "Would you say the household you grew up in was chaotic and disorganized?" and "Would you say you were neglected while you were growing up, left on your own to fend for yourself?". Because the RFQ lacks of an Italian validation, we performed a split-sample Exploratory Factor Analysis (EFA) and a Confirmatory Factor Analysis (CFA) of the RFQ (supplementary materials).

\section{Resilience Scale for Adults}

Resilience was assessed using the Resilience Scale for Adults (RSA), Italian version (RSA) (Capanna, Stratta, Hjemdal, Collazzoni, \& Rossi, 2015; Friborg et al., 2003). The RSA is a 7-point Likert scale of 33 items grouped into 6 factors, namely Perception of Self: concerning self-confidence and positive outlook; Planned Future: concerning a positive outlook on one's own future; Social Competence: concerning individual's own perception of her/his ability to initiate verbal contact and flexibility in social interactions; Structured Style: concerning goal oriented planning ability; Family Cohesion: concerning shared values and cohesion within one's family; Social Resources: concerning social support and feeling of cohesion outside the family. Psychometric details of the Italian version of the RSA can be found elsewhere (Capanna et al., 2015). In this sample, alpha coefficient was 0.92 .

\section{Prodromal Questionnaire-16, Italian version}

The Italian version of the Prodromal Questionnaire-16 (iPQ-16) (Azzali et al., 2018) was used to assess the presence of PLEs. iPQ-16 is a 16-itmes self-report instrument that explores the presence/absence of 16 PLEs, including perceptual aberrations/hallucinations, unusual thought content/delusions, and two negative symptoms, and their associated psychological distress. iPQ-16 scores the number of actual PLE endorsed, ranging from 0 to 16, and a distress score on a 4-point likert scale ranging from 0 to 48. Although the iPQ-16 was originally designed as a screening tool for individuals at UHR in help-seeking populations, several studies have used this instrument in the general population as a measure of PLEs (Gawęda, Göritz, \& Moritz, 2019; Gawęda, Pionke, et al., 2019; Mętel et al., 2020; Sengutta et al., 2019). Because different cut-off points have been proposed for different populations (Savill, D'Ambrosio, Cannon, \& Loewy, 2018), we chose to use the iPQ-16 score as a continuous rather than binary variable in order to avoid sensibility/specificity issues. For the sake of clarity of exposure, we will present only the results of the iPQ-16 endorsed score, as the results of the distress score were substantially overlapping.

\section{Statistical analysis}

All the following statistics were performed using Stata $13^{\circledR}$.

Firstly, descriptive statistics were performed on demographic variables, RSA, RFQ and iPQ-16.

Secondly, Confirmatory Factor Analysis (CFA) of RSA with Variance-Covariance matrix Maximum Likelihood estimation (ML) was performed on two theory-driven models: a one-dimensional solution, with the six factors loading on a single second order latent variable, and a two-dimension solution with "Perception Of Self", "Planned Future", "Social Competence" and "Structured Style" loading on one latent variable named "PERSONAL RESILIENCE", and "Family Cohesion" and "Social Resources" loading on a second latent variable named "CONTEXTUAL RESILIENCE". The two models have been contrasted (Morote et al., 2017) in a Spanish-language version, with better fit indices for the 
medRxiv preprint doi: https://doi.org/10.1101/2020.05.18.20106237; this version posted May 26, 2020. The copyright holder for this preprint

(which was not certified by peer review) is the author/funder, who has granted medRxiv a license to display the preprint in perpetuity.

All rights reserved. No reuse allowed without permission.

two-dimension model. To the best of our knowledge, no direct comparison of the two alternative models has been reported in a non-clinical Italian sample. Goodness-of-fit indices were computed for the two models, including relative fit indices Aikake's Information Criteria (AIC) and Bayesian Information Criteria (BIC) that allow goodness of fit comparison between models.

Once a two-dimension structure of RSA was confirmed, a mediation analysis was performed within a SEM framework. RFQ total score and iPQ-16 total score were modelled, respectively, as exogenous and response variables. The two latent factors of resilience, Personal and Contextual Resilience, were included as simultaneous mediators. Observed scores of the six resilience factors, computed from the RSA questionnaire were used as manifest indicators of both latent variables for the sake of simplicity of calculation.

An initial model including all possible paths connecting exogenous variable, mediators and the response was specified.

This model was further modified according to modification indices.

Mediation was assessed inspecting the indirect effect percentile and bias-corrected $95 \%$ confidence interval, according to Hayes and Preacher method. Hayes and Preacher bootstrapping method is currently considered the best method for assessing significance of the indirect effects (Shrout \& Bolger, 2002).

\section{Results}

Characteristics of the sample

Demographic characteristics of the sample are shown in table 1. Five hundred participants completed the questionnaire, of which 356 (71.2\%) were female. Mean age in the sample was 25.52 ( $\mathrm{SD}=5.84)$. Summary statistics for RFQ, RSA and iPQ16 are reported in table 1.

\section{RFQ Exploratory and Confirmatory Factor analysis}

EFA performed on 250 randomly selected participants indicate a single-factor structure with $80 \%$ of variance explained, factor loadings comprised between 0.80 and 0.25 for the 10 positive items, and between -0.54 and -0.80 for the 3 reversed-scored items. Reliability $\square$ coefficient was 0.87 with 0.39 average interitem covariance. CFA initially showed unsatisfactory fit indices. After inspection of modification indices, covariances between items were added accordingly. Fit indices in the resulting model were satisfactory, with RMSEA=0.083, CFI=0.91 and CD=0.87.

\section{CFA of RSA}

CFA fit indices for the unidimensional and two-dimension proposed models are reported in Table 2. A graphical representation of the two-dimension model is presented in Figure 1. Both models showed adequate fit, and did not require post-hoc re-specification based on modification indices. Overall, the two-dimension model displayed slightly better fit indices, with lower AIC and BIC. Reaching convergence was particularly difficult for the two-dimension model and specification of starting values from a simplified model was necessary. 
medRxiv preprint doi: https://doi.org/10.1101/2020.05.18.20106237; this version posted May 26, 2020. The copyright holder for this preprint

(which was not certified by peer review) is the author/funder, who has granted medRxiv a license to display the preprint in perpetuity.

All rights reserved. No reuse allowed without permission.

Figure 2 reports the path diagram with standardized coefficients. All path coefficients were statistically significant except for the direct effect of Contextual Resilience on iPQ-16. After the initial model specification and inspection of the modification indices, a covariance between Social Resources and Social Competence was added. The resulting goodness of fit indices were as follows: $\chi_{(15)}^{2}=56.804(\mathrm{p}<0.001)$; RMSEA=0.075 [0.055, 0.096]; CFI=0.968; $\mathrm{SRMR}=0.040 ; \mathrm{CD}=0.544$. The estimates of direct, indirect and total effects are reported in Table 3. Because the direct effect between Contextual Resilience and iPQ-16 was not significant, we did not go further in assessing mediation through this path. The indirect effect between RFQ and iPQ-16 through Personal Resilience was 0.028 [0.013, 0.044]. As the total effect of RFQ on iPQ-16 was 0.1 [0.07, 0.13], 48.7\% of the effect of RFQ on iPQ-16 was mediated by RSA as a whole, with $27.4 \%$ through Personal Resilience.

We further tested the significance of the indirect effect using bias-corrected and percentile bootstrapped 95\%CI inspection. Unstandardized indirect effects were computed for each of 1000 bootstrapped samples, and the $95 \%$ confidence interval was computed by determining the indirect effects at the 2.5 th and 97.5 th percentiles. The bootstrapped Percentile and Bias-corrected 95\% CI of the indirect effect through Personal Resilience were respectively $[0.013,0.044]$ and $[0.014,0.046]$. Thus, the indirect effect via Personal Resilience was statistically significant.

\section{Discussion}

\section{Summary of findings}

In the present study, we analyzed in detail the mediational effect of resilience between risky family environment and PLEs in a relatively large sample of university students.

In particular, we successfully decomposed resilience as measured by the RSA into two separated components using CFA: a personal component representing individual resiliency assets, and a contextual component representing resilience resources associated with social and familial aspects. Our results show that, although a unidimensional model adequately fits the data, a bidimensional model fits the data in a better way. Our finding is consistent with one previous CFA on a Spanish-speaking sample (Morote et al., 2017). Furthermore, a recent network analysis supports a four domain model with personal competence being the central node between "support" (family cohesion + social resources), "structured style" and "social competence", a finding that is consistent with our CFA (Briganti \& Linkowski, 2019). Overall, our findings are in line with the conceptualization of resilience proposed by Fergus and Zimmerman that clearly separate personal assets from social and interpersonal resources (Fergus \& Zimmerman, 2005). Next, we found evidence that personal and contextual domains of resilience have substantially different roles relative to risky family environment and PLEs, with nearly $28 \%$ of the effect of risky family on PLEs being mediated through personal resilience factors. Risky family environment had a substantial impact on contextual resilience, however no effect from contextual resilience to PLEs was observed in our model.

\section{Previous literature}

Mediators between childhood adversity, including a risky family environment, and psychosis risk are a central topic in current research. Although resilience has been previously investigated as a key psychological factor for psychosis risk and psychosis outcome (Mętel et al., 2020; Ruzibiza, Grattan, Eder, \& Linscott, 2018), this is the first study that addresses in detail the differential role of two separate components of resilience as risk factors for PLEs. The main narrative in current research conceptualizes resilience as a rather stable protective factor against childhood adversity 
medRxiv preprint doi: https://doi.org/10.1101/2020.05.18.20106237; this version posted May 26, 2020. The copyright holder for this preprint

(which was not certified by peer review) is the author/funder, who has granted medRxiv a license to display the preprint in perpetuity.

All rights reserved. No reuse allowed without permission.

and poor mental health outcomes (Southwick, Bonanno, Masten, Panter-Brick, \& Yehuda, 2014). According to this view, resilience should be modelled as a potential moderator, rather than a mediator, of the effect of stressful or traumatic events on psychotic risk. This hypothesis wasn't confirmed in a rather small sample of undergraduate students (Ruzibiza et al., 2018). On the other hand, invoking resilience as a mediator between childhood adversity and poor psychological outcomes implies the existence of a direct effect of early traumatic experiences on resilience itself, making low resilience a risk factor (Kraemer et al. 2001) for stress-related outcomes. More in general, invoking resilience as a mediator assumes that a given independent variable could exert an effect on resilience itself. This assumption suggests that resilience is a dynamic and changeable constructs (Stainton et al., 2018), hence several factors that could promote fluctuations of resilience over time should be taken into account in resilience research.

Our results are in line with the view that both personal and contextual resilience are affected by a risky family environment: in particular, personal assets may be weakly affected by environmental factors, while showing a large impact on PLEs, carrying the largest part of the mediated effect on PLEs.

In our model, the effect of risky family environment on Contextual Resilience could be due to partial overlapping of the contents of the two constructs. Social resources, on the other hand, have been confirmed to act as moderators by one of the few longitudinal studies available (Crush et al., 2018; Riches et al., 2019). The presence of good social resources, in fact, could be spared from the destructive effects of a stressful familial environment. Nevertheless, in order to access environmental social resources, one needs to be socially competent in the first place, a functional domain that has been confirmed to be impaired in individuals with PLE (Chisholm et al., 2018). Social competence is a particular factor in resilience as assessed by RSA. Inspecting our CFA, social competence has the lesser loading on personal resilience, while in our path model modification indices required adding a covariance $(0.3)$ between social competence and social resources, indicating that social competence and social resources are the links between personal and interpersonal resilience.

The role of resilience as a protective factor could be questioned as the link between a harsh familial environment and low personal resilience suggests that early adversity may hinder the development of functional personal resilience resources. These in turn may play a role in the development of PLEs, for example failing to protect the individual from recent stressors (Bhavsar et al., 2019).

One model that could involve both a moderator and mediator role of resilience could be a dual-stage one, in which early traumatic experiences negatively affect resilience in the first place, and resilience in turn moderates the response to subsequent traumatic events.

This study opens important questions about the factor structure of resilience in different populations, namely helpseeking populations such as At Risk Mental States, Ultra-High risk samples and First Episode Psychosis. A number of factors could affect the latent structure of resilience in such populations, so exploring this issue in further studies could be of great relevance.

\section{Limitations}

Our study has some conceptual and methodological limitations.

Firstly, Risky Family Questionnaire (RFQ) was not previously validated. In order to address this issue, we have performed both EFA and CFA. It worth noting that RFQ focuses on dysfunctional familial environment rather than childhood traumatic experiences in the broadest sense. 
Secondly, some statistical limitations are present on the RSA CFA: the two-dimensional model has been particularly difficult to converge, and several interventions of the initial values were made in order to reach convergence. This is possibly due to the fact that only two factors were loaded onto "Interpersonal Resilience". Despite having convergence issues, we chose not to re-specify the model because we aimed at specifying a soundly theory-driven model in the first place.

Finally, some of the interpretations we have provided in the discussion may be flawed by the cross-sectional design of this study. When addressing traumatic experiences using a retrospective self-report instrument, as the vast majority of studies actually do, recall bias is a major concern that could be eliminated only by a longitudinal non self-report design.

\section{Conclusions}

The main findings of this study suggest that resilience could be considered two-dimensional construct. Personal resilience, as opposite to contextual resilience, shows a mediating effect within the putative causal pathways from risky family environment to PLE. These evidence could have a clinical relevance as they suggest that personal and contextual resilience factors should be addressed separately in the context of early of early interventions, and could represent an important therapeutic target in subjects exposed to childhood adversity. One possible extension of our findings, in future studies, could be in assessing the differential impact of early and later traumatic events in both general and clinical populations towards PLEs, as well as a dual mediation/moderation model. Under a clinical perspective, exploring in detail resiliency resources could help to a better design of individualized tailored treatment plans in young help-seeking individuals with a history of risky family environment.

\section{Acknowledgments}

The authors would like to thank all the participants to the study. No funding was received for this study. 


\section{Bibliography}

Azzali, S., Pelizza, L., Paterlini, F., Garlassi, S., Scazza, I., Chiri, L. R., ... Raballo, A. (2018). Reliability of the Italian version of the 16-item Prodromal Questionnaire (iPQ-16) for psychosis risk screening in a young help-seeking community sample. Journal of Psychopathology, 24(1), 16-23.

Bentall, R. P., de Sousa, P., Varese, F., Wickham, S., Sitko, K., Haarmans, M., \& Read, J. (2014). From adversity to psychosis: pathways and mechanisms from specific adversities to specific symptoms. Social Psychiatry and Psychiatric Epidemiology, 49(7), 1011-1022. https://doi.org/10.1007/s00127-014-0914-0

Bhavsar, V., Boydell, J., McGuire, P., Harris, V., Hotopf, M., Hatch, S. L., .. Morgan, C. (2019). Childhood abuse and psychotic experiences - evidence for mediation by adulthood adverse life events. Epidemiology and Psychiatric Sciences, 28(3), 300309. https://doi.org/10.1017/S2045796017000518

Briganti, G., \& Linkowski, P. (2019). Item and domain network structures of the Resilience Scale for Adults in 675 university students. Epidemiology and Psychiatric Sciences, 1-9. https://doi.org/10.1017/S2045796019000222

Capanna, C., Stratta, P., Hjemdal, O., Collazzoni, A., \& Rossi, A. (2015). The Italian validation study of the Resilience Scale for Adults (RSA). Applied Psychology Bulletin, 272(63), 16-24.

Chisholm, K. E., Wigman, J. T. W., Hallett, D., Woodall, T., Mahfouda, S., Reniers, R. L. E. P., ... Lin, A. (2018). The role of coping in the association between subclinical psychotic experiences and functioning: A within study replication in two independent adolescent samples. Schizophrenia Research. https://doi.org/10.1016/j.schres.2018.05.022

Crush, E., Arseneault, L., Moffitt, T. E., Danese, A., Caspi, A., Jaffee, S. R., ... Fisher, H. L. (2018). Protective factors for psychotic experiences amongst adolescents exposed to multiple forms of victimization. Journal of Psychiatric Research. https://doi.org/10.1016/j.jpsychires.2018.06.011

Felitti, V. J., Anda, R. F., Nordenberg, D., Williamson, D. F., Spitz, A. M., Edwards, V., ... Marks, J. S. (1998). Relationship of Childhood Abuse and Household Dysfunction to Many of the Leading Causes of Death in Adults: The Adverse Childhood Experiences (ACE) Study. American Journal of Preventive Medicine, 14(4), 245-258. https://doi.org/10.1016/S07493797(98)00017-8

Fergus, S., \& Zimmerman, M. A. (2005). ADOLESCENT RESILIENCE: A Framework for Understanding Healthy Development in the Face of Risk. Annual Review of Public Health, 26(1), 399-419. https://doi.org/10.1146/annurev.publhealth.26.021304.144357

Fisher, H. L., Schreier, A., Zammit, S., Maughan, B., Munafò, M. R., Lewis, G., \& Wolke, D. (2013). Pathways between childhood victimization and psychosis-like symptoms in the ALSPAC birth cohort. Schizophrenia Bulletin, 39(5), 1045-1055. https://doi.org/10.1093/schbul/sbs088

Freeman, D., \& Garety, P. (2014). Advances in understanding and treating persecutory delusions: A review. Social Psychiatry and Psychiatric Epidemiology, 49(8), 1179-1189. https://doi.org/10.1007/s00127-014-0928-7

Friborg, O., Barlaug, D., Martinussen, M., Rosenvinge, J. H., \& Hjemdal, O. (2005). Resilience in relation to personality and intelligence. International Journal of Methods in Psychiatric Research, 14(1), 29-42. Retrieved from http://www.ncbi.nlm.nih.gov/pubmed/16097398

Friborg, O., Hjemdal, O., Rosenvinge, J. H., \& Martinussen, M. (2003). A new rating scale for adult resilience: what are the central protective resources behind healthy adjustment? International Journal of Methods in Psychiatric Research, 12(2), 65-76. https://doi.org/10.1002/mpr.143

Gawęda, Ł., Göritz, A. S., \& Moritz, S. (2019). Mediating role of aberrant salience and self-disturbances for the relationship between childhood trauma and psychotic-like experiences in the general population. Schizophrenia Research, 206, 149-156. https://doi.org/10.1016/j.schres.2018.11.034

Gawęda, Ł., Pionke, R., Krężołek, M., Frydecka, D., Nelson, B., \& Cechnicki, A. (2019). The interplay between childhood trauma, cognitive biases, psychotic-like experiences and depression and their additive impact on predicting lifetime suicidal behavior in young adults. Psychological Medicine, 1-9. https://doi.org/10.1017/S0033291718004026

Glaser, B., Ades, A. E., Lewis, S., Emmet, P., Lewis, G., Smith, G. D., \& Zammit, S. (2010). Perinatal folate-related exposures and risk of psychotic symptoms in the ALSPAC birth cohort. Schizophrenia Research, 120(1-3), 177-183. https://doi.org/10.1016/j.schres.2010.03.006

Horwood, J., Salvi, G., Thomas, K., Duffy, L., Gunnell, D., Hollis, C., ... Harrison, G. (2008). IQ and non-clinical psychotic symptoms in 12-year-olds: Results from the ALSPAC birth cohort. British Journal of Psychiatry, 193(3), 185-191. https://doi.org/10.1192/bjp.bp.108.051904

Linscott, R. J., \& Van Os, J. (2013). An updated and conservative systematic review and meta-analysis of epidemiological evidence on psychotic experiences in children and adults: On the pathway from proneness to persistence to dimensional expression across mental disorders. Psychological Medicine, 43(6), 1133-1149. https://doi.org/10.1017/S0033291712001626

McGrath, J. J., McLaughlin, K. A., Saha, S., Aguilar-Gaxiola, S., Al-Hamzawi, A., Alonso, J., ... Kessler, R. C. (2017). The association between childhood adversities and subsequent first onset of psychotic experiences: a cross-national analysis of 23 998 respondents from 17 countries. Psychological Medicine, 47(7), 1230-1245. https://doi.org/10.1017/S0033291716003263

McGrath, J. J., Saha, S., Al-Hamzawi, A., Alonso, J., Bromet, E. J., Bruffaerts, R., ... Kessler, R. C. (2015). Psychotic Experiences in the General Population. JAMA Psychiatry, 72(7), 697. https://doi.org/10.1001/jamapsychiatry.2015.0575

Mętel, D., Arciszewska, A., Daren, A., Pionke, R., Cechnicki, A., Frydecka, D., \& Gawęda, Ł. (2020). Mediating role of cognitive biases, resilience and depressive symptoms in the relationship between childhood trauma and psychotic $\square$ like experiences in 
young adults. Early Intervention in Psychiatry, 14(1), 87-96. https://doi.org/10.1111/eip.12829

Morgan, C., \& Gayer-Anderson, C. (2016). Childhood adversities and psychosis: Evidence, challenges, implications. World Psychiatry, 15(2), 93-102. https://doi.org/10.1002/wps.20330

Morote, R., Hjemdal, O., Uribe, P. M., \& Corveleyn, J. (2017). Psychometric properties of the Resilience Scale for Adults (RSA) and its relationship with life-stress, anxiety and depression in a Hispanic Latin-American community sample. PLoS ONE, 12(11), 1-20. https://doi.org/10.1371/journal.pone.0187954

Peh, O. H., Rapisarda, A., \& Lee, J. (2019). Childhood adversities in people at ultra-high risk (UHR) for psychosis: a systematic review and meta-analysis. Psychological Medicine, 49(07), 1089-1101. https://doi.org/10.1017/S003329171800394X

Rauschenberg, C., van Os, J., Cremers, D., Goedhart, M., Schieveld, J. N. M., \& Reininghaus, U. (2017). Stress sensitivity as a putative mechanism linking childhood trauma and psychopathology in youth's daily life. Acta Psychiatrica Scandinavica. https://doi.org/10.1111/acps. 12775

Riches, S., Arseneault, L., Bagher-Niakan, R., Alsultan, M., Crush, E., \& Fisher, H. L. (2019). Protective factors for early psychotic phenomena among children of mothers with psychosis. Frontiers in Psychiatry. https://doi.org/10.3389/fpsyt.2018.00750

Rossetti, M. C., Tosone, A., Stratta, P., Collazzoni, A., Santarelli, V., Guadagni, E., ... Rossi, A. (2017). Different roles of resilience in depressive patients with history of suicide attempt and no history of suicide attempt. Revista Brasileira de Psiquiatria, 39(3), 216-219. https://doi.org/10.1590/1516-4446-2016-2045

Rossi, A., Amore, M., Galderisi, S., Rocca, P., Bertolino, A., Aguglia, E., ... Bracale, N. (2018). The complex relationship between self-reported 'personal recovery' and clinical recovery in schizophrenia. Schizophrenia Research, 192, 108-112. https://doi.org/10.1016/j.schres.2017.04.040

Rossi, A., Galderisi, S., Rocca, P., Bertolino, A., Rucci, P., Gibertoni, D., ... Cardillo, S. (2017). Personal resources and depression in schizophrenia: The role of self-esteem, resilience and internalized stigma. Psychiatry Research, 256(June), 359-364. https://doi.org/10.1016/j.psychres.2017.06.079

Rossi, R., Zammit, S., Button, K. S., Munafò, M. R., Lewis, G., \& David, A. S. (2016). Psychotic experiences and working memory: A population-based study using signal-detection analysis. PLoS ONE, 11(4), e0153148. https://doi.org/10.1371/journal.pone.0153148

Ruzibiza, C., Grattan, R. E., Eder, R., \& Linscott, R. J. (2018). Components of schizophrenia liability are not uniformly associated with stress sensitivity, resilience, and coping. Psychiatry Research. https://doi.org/10.1016/j.psychres.2017.11.039

Savill, M., D’ Ambrosio, J., Cannon, T. D., \& Loewy, R. L. (2018). Psychosis risk screening in different populations using the Prodromal Questionnaire: A systematic review. Early Intervention in Psychiatry, 12(1), 3-14. https://doi.org/10.1111/eip.12446

Sengutta, M., Gawęda, Ł., Moritz, S., \& Karow, A. (2019). The mediating role of borderline personality features in the relationship between childhood trauma and psychotic-like experiences in a sample of help-seeking non-psychotic adolescents and young adults. European Psychiatry, 56, 84-90. https://doi.org/10.1016/j.eurpsy.2018.11.009

Serrone, D., Parnanzone, S., Pizziconi, G., Talevi, D., Curtarello, E. M. A., Pacitti, F., .. Rossi, R. (2019). Source monitoring task in a sample of in-patients with verbal auditory hallucinations compared to control sample. Rivista Di Psichiatria, 54(2), 91-94. https://doi.org/10.1708/3142.31250

Shrout, P. E., \& Bolger, N. (2002). Mediation in experimental and nonexperimental studies: new procedures and recommendations. Psychological Methods.

Southwick, S. M., Bonanno, G. A., Masten, A. S., Panter-Brick, C., \& Yehuda, R. (2014). Resilience definitions, theory, and challenges: Interdisciplinary perspectives. European Journal of Psychotraumatology, 5(1), 25338. https://doi.org/10.3402/ejpt.v5.25338

Stainton, A., Chisholm, K., Kaiser, N., Rosen, M., Upthegrove, R., Ruhrmann, S., \& Wood, S. J. (2018). Resilience as a multimodal dynamic process. Early Intervention in Psychiatry, (June), 1-8. https://doi.org/10.1111/eip.12726

Thapar, A., Heron, J., Jones, R. B., Owen, M. J., Lewis, G., \& Zammit, S. (2012). Trajectories of change in self-reported psychoticlike experiences in childhood and adolescence. Schizophrenia Research, 140(1-3), 104-109. https://doi.org/10.1016/j.schres.2012.06.024

Thomas, K., Harrison, G., Zammit, S., Lewis, G., Horwood, J., Heron, J., ... Gunnell, D. (2009). Association of measures of fetal and childhood growth with non-clinical psychotic symptoms in 12-year-olds: The ALSPAC cohort. British Journal of Psychiatry, 194(6), 521-526. https://doi.org/10.1192/bjp.bp.108.051730

Trotta, A., Murray, R. M., \& Fisher, H. L. (2015). The impact of childhood adversity on the persistence of psychotic symptoms: A systematic review and meta-analysis. Psychological Medicine. https://doi.org/10.1017/S0033291715000574

Varese, F., Smeets, F., Drukker, M., Lieverse, R., Lataster, T., Viechtbauer, W., ... Bentall, R. P. (2012). Childhood adversities increase the risk of psychosis: A meta-analysis of patient-control, prospective-and cross-sectional cohort studies. Schizophrenia Bulletin. https://doi.org/10.1093/schbul/sbs050

Williams, J., Bucci, S., Berry, K., \& Varese, F. (2018). Psychological mediators of the association between childhood adversities and psychosis: A systematic review. Clinical Psychology Review, 65(January), 175-196. https://doi.org/10.1016/j.cpr.2018.05.009

Zammit, S., Kounali, D., Cannon, M., David, A. S., Gunnell, D., Heron, J., .. Lewis, G. (2013). Psychotic Experiences and Psychotic Disorders at Age 18 in Relation to Psychotic Experiences at Age 12 in a Longitudinal Population-Based Cohort Study. American Journal of Psychiatry, 170(7), 742-750. https://doi.org/10.1176/appi.ajp.2013.12060768 
medRxiv preprint doi: https://doi.org/10.1101/2020.05.18.20106237; this version posted May 26, 2020. The copyright holder for this preprint (which was not certified by peer review) is the author/funder, who has granted medRxiv a license to display the preprint in perpetuity.

All rights reserved. No reuse allowed without permission.

Table 1. Demographic characteristics of the sample and descriptive statistics of variables of interest

Age

Range

Mean (SD)

Gender, $\mathbf{n}(\%)$

Female

Male

Education (years)

Range

Mean (SD)

RFQ

Range

Mean (SD)

RSA, mean (SD)

Perception Of The Self

Planned Future

Social Competence

Family Cohesion

Social Resources

Structured Style

iPQ-16 Endorsed score,

mean (SD)
18-62

$25.52(5.84)$

$356(71.2 \%)$

$144(28.80 \%)$

8-30

17.35 (2.91)

13-61

$26.54(8.68)$

4.69 (1.28)

$4.70(1.51)$

$4.88(1.23)$

$4.92(1.53)$

$5.63(1.19)$

$5.12(1.22)$

$4.02 \quad(3.06)$ 
Figure 1: Confirmatory factor analysis of RSA with standardized coefficients.

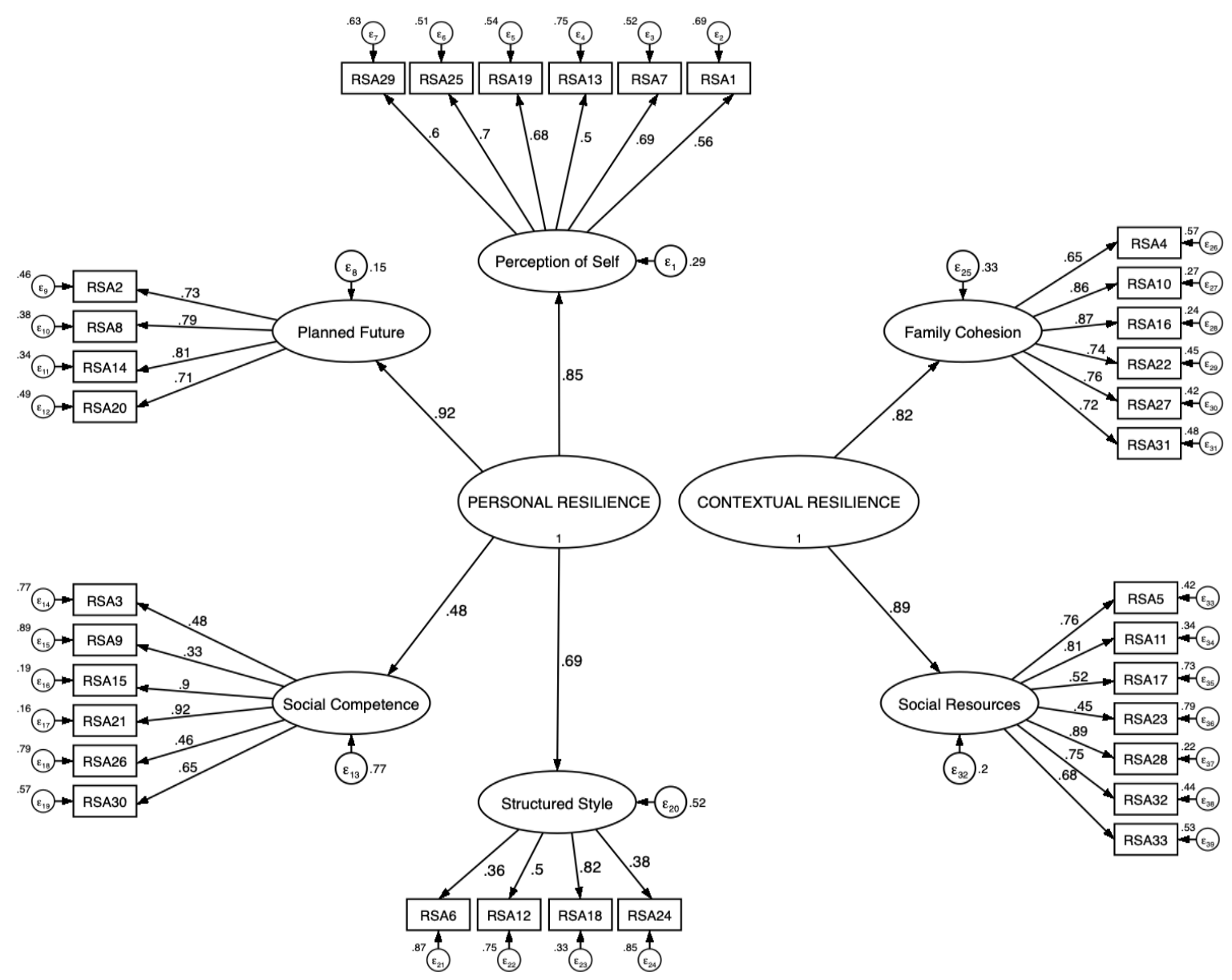

Table 2. Goodness-of-fit indices of Confirmatory Factor Analysis of RSA

\begin{tabular}{lll}
\hline Fit Index & One-dimensional & Two-dimension \\
\hline$\chi^{\mathbf{2}}{ }_{(489)}$ & 1310.217 & 1236.808 \\
$\mathbf{p}$ & 0.000 & 0.000 \\
RMSEA & $0.058[0.054,0.062]$ & $0.055[0.052,0.059]$ \\
AIC & 58920.746 & 58847.337 \\
BIC & 59363.070 & 59289.660 \\
CFI & 0.891 & 0.900 \\
SRMR & 0.088 & 0.139 \\
CD & 0.886 & 0.986 \\
\hline
\end{tabular}

RSA: Resilience Scale for Adults, Italian version; RMSEA: Root mean squared error of approximation; AIC: Akaike's information criterion; BIC: Bayesian information criterion; CFI Comparative fit index; SRMR: Standardized root mean squared residual; CD: Coefficient of determination. 
Figure 2. Path model with standardized coefficients.

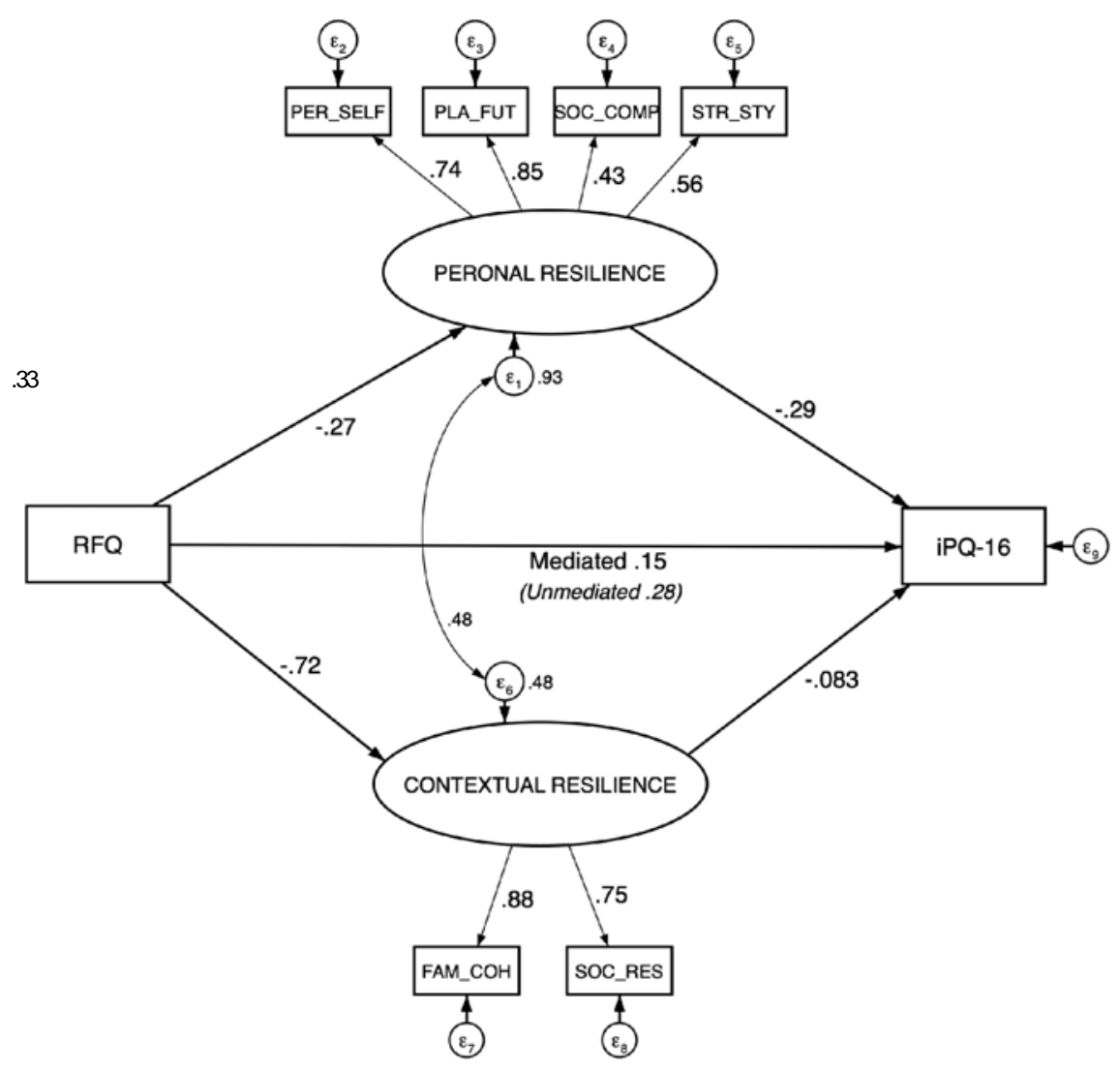

Results for the structural equation model: rectangles represent indicator variables; ovals, latent variables. Numbers by single-headed arrows reflect standardized regression weights. PER_SELF: perception of the self; PLA_FUT: planned future; SOC_COMP: social competence; FAM_COH: family cohesion; SOC_RES social resources; STR_STY: structured style

Table 3. Path model summary with direct, indirect and total effects.

Coef.

Direct Effects on iPQ-16

Personal Resilience

Contextual Resilience

$R F Q$

Indirect effects on iPQ-16

via Personal Resilience

$0.03 *$

$[0.01,0.04]$

$[0.013,0.044]^{\mathrm{a}}$

$[0.014,0.046]^{\mathrm{b}}$

via Contextual Resilience

0.02

$[-0.02,0.06]$

Total effect on iPQ-16

Personal Resilience

Contextual Resilience

$-0.69 * * *$

$-0.19$

$[-0.97,-0.41]$

$R F Q$

$0.10 * * *$

iPQ-16: Prodromal Questionnaire - italian version; RFQ: Risky Family Questionnaire; a: bootstrapped Percentile 95\% CI; b: bootstrapped Bias-corrected $95 \%$ CI; *p $<0.05 ; * * \mathrm{p}<0.005 ; * * * \mathrm{p}<0.001$. 